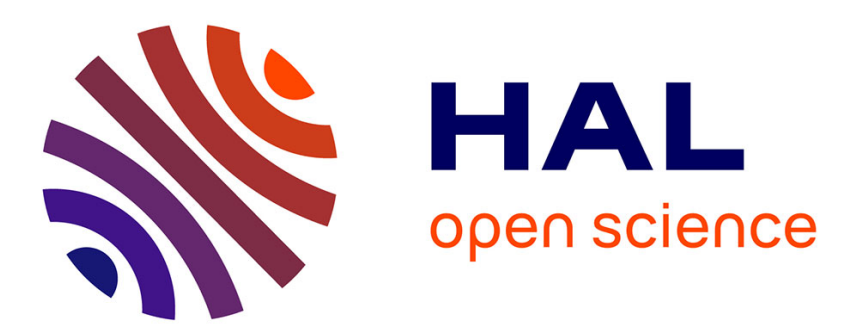

\title{
Vertical distribution of Skewness and asymmetry in a boundary layer on a mobile bed. Experiment and k- $\omega$ model comparison
}

Léandro Suarez Atias, Eric Barthélemy, Céline Berni, Julien Chauchat, Hervé Michallet, Rodrigo Cienfuegos

\section{To cite this version:}

Léandro Suarez Atias, Eric Barthélemy, Céline Berni, Julien Chauchat, Hervé Michallet, et al.. Vertical distribution of Skewness and asymmetry in a boundary layer on a mobile bed. Experiment and k- $\omega$ model comparison. La Houille Blanche - Revue internationale de l'eau, 2014, 2, pp.88-94. 10.1051/lhb/2014020 . hal-01141896

\author{
HAL Id: hal-01141896 \\ https://hal.science/hal-01141896
}

Submitted on 14 Apr 2015

HAL is a multi-disciplinary open access archive for the deposit and dissemination of scientific research documents, whether they are published or not. The documents may come from teaching and research institutions in France or abroad, or from public or private research centers.
L'archive ouverte pluridisciplinaire HAL, est destinée au dépôt et à la diffusion de documents scientifiques de niveau recherche, publiés ou non, émanant des établissements d'enseignement et de recherche français ou étrangers, des laboratoires publics ou privés. 


\title{
Vertical distribution of Skewness and asymmetry in a boundary layer on a mobile bed. Experiment and $\boldsymbol{k}-\omega$ model comparison
}

\author{
Leandro SUAREZ1,2, Eric BARTHELEMY², Céline BERNI ${ }^{3}$, Julien CHAUCHAT², \\ Hervé MICHALLET ${ }^{2}$, Rodrigo CIENFUEGOS ${ }^{1,4}$
}

\author{
${ }^{1}$ Departamento de Ingeniería Hidráulica y Ambiental, Pontificia Universidad Católica de Chile, Vicuña Mackenna \\ 4860, casilla 306, correo 221, Santiago de Chile,Chile.e-mail: lsuarez2@uc.cl racienfu@ing.puc.cl \\ ${ }^{2}$ Laboratoire des Ecoulements Géophysiques et Industriels (UJF, GINP, CNRS), BP53, 38041 Grenoble Cedex 9, \\ France.e-mail: eric.barthelemy@legi.grenoble-inp.fr; julien.chauchat@legi.grenoble-inp.fr; herve.michallet@legi.grenoble-inp.fr \\ ${ }^{3}$ IRSTEA, UR HHLY, équipe hydraulique des rivières, Centre de Lyon, 5 rue de la Doua, CS 70077, 69626 Villeurbanne Cedex. \\ e-mail: celine.berni@irstea.fr \\ ${ }^{4}$ CIGIDEN, Centro Nacional de Investigación para la Gestión Integrada de Desastres Naturales, Vicuña Mackenna \\ 4860, casilla 306, correo 221, Santiago de Chile, Chile
}

\begin{abstract}
As the waves approach the coast, non-linearities become increasingly stronger. The interactions between the waves and loose bottoms then generate complex features within the turbulent boundary layer, which are difficult to measure and model. Experiments involving non-linear wave propagation over a mobile bed with detailed boundary layer velocity measurements and bottom elevations are presented. These data suggest a transformation in velocity time series as they are measured closer to the bed within the boundary layer with an increase in velocity skewness and a reduction in asymmetry. Additionally the vertical diffusion of momentum within the boundary layer is shown to be one order of magnitude larger than that over fixed beds. A k- $\omega$ model accounting for the measured bed level variations is used to mimic the flow in the boundary layer. In this work we present a strategy to combine bottom level variations with a k- $\omega$ model and show that it is possible to reproduce the observed experimental results. The bed vertical mobility is shown to be largely responsible for additional vertical diffusion of momentum within the boundary layer.
\end{abstract}

Key-words: non-linear waves, boundary layer, diffusivity, mobile bed

\section{Distribution verticales d'asymétrie et de skewness dans une couche limite sur fond mobile. Une comparaison expériences - modèle k- $\omega$}

\begin{abstract}
RÉSUMÉ. - Lorsque les vagues se rapprochent de la côte, leurs non linéarités augmentent. Les interactions entre les vagues et un fond mobile produisent des effets complexes sur la couche limite turbulente pariétale qui sont difficiles à mesurer et à modéliser. Des mesures réalisées dans un modèle physique de propagation de vagues non-linéaires sur fond mobile sont présentées. L'analyse conjointe des profils de vitesse et d'évolution du fond suggère une transformation au sein de la couche limite, par laquelle l'asymétrie horizontale des vitesses (skewness) augmente au fur et à mesure que l'asymétrie (skewness de l'accélération) diminue en se rapprochant du fond. De plus on constate que la diffusion verticale dans cette couche limite est plus importante sur fond mobile que sur fond fixe. Dans ce travail nous présentons une stratégie pour combiner les variations verticales du fond avec un modèle $k-\omega$ et montrons que celle-ci permet de reproduire les mesures expérimentales. Nous montrons que la mobilité verticale du fond est responsable de l'augmentation de la diffusion verticale de quantité de movement dans la couche limite.
\end{abstract}

Mots-clés : houle non-linéaire, couche limite, diffusivité, lit mobile

\section{INTRODUCTION}

Complex flow-sediment interactions are observed within the turbulent boundary layer produced under nearshore waves propagating over loose bottoms. When approaching the coast, the shoaling waves undergo non-linear transformations and dissipation during breaking that impact the boundary layer dynamics.

Since the pioneering work by [Bailard, 1981] it is of common understanding that free stream velocity skewness is a key parameter for estimating the rate of sediment transport. In the last decade it has been suggested that asymmetric waves also produce net sediment transport (see for instance Ruessink et al., [2009]). Bottom velocity skewness and asymmetry depend on how the boundary layer develops. In this paper we will focus on the study of the turbulent boundary layer resulting from surf zone wave propagation over a mobile bed.

Using the experiments over a scaled sandy bottom of Berni et al., [2013], we attempt to characterize the near bed evolution of velocity profiles and its relation with free stream velocities. The experiments also showed an intriguing strong vertical momentum diffusion in the turbulent boundary layer. Vertical diffusion of momentum is easily quantified by computing the boundary layer thickness defined, for instance, as the height where the defect velocity is $5 \%$ of the free stream velocity. 
The laminar boundary layer thickness is a function of the Stokes length $\delta$ which reads,

$$
\delta=\sqrt{\frac{\nu T}{\pi}}
$$

where $v$ is the water viscosity and $T$ is the wave period. The laminar boundary layer thickness is roughly $3 \delta$ and is generally very small. For the experimental conditions studied by Berni et al., [2013] its value is of $\approx 3 \mathrm{~mm}$. For rough turbulent boundary layers on fixed sand beds the boundary layer thickness $\delta_{t}$ can be estimated empirically as [Sleath, 1987],

$$
\frac{\delta_{t}}{k_{s}}=0.27\left(\frac{A}{k_{s}}\right)^{0.67}
$$

where $A$ is the fluid particle excursion at the bottom, $k_{s}$ the Nikuradse equivalent roughness. [Sleath, 1987] recommends the use of $k_{s}=2.5 d_{50}, d_{50}$ being the median grain diameter. In the case of the $T=2.5 \mathrm{~s}$ experiments of Berni et al., [2013] the value of the turbulent boundary layer thickness estimated by (2) is $\delta_{t} \approx 6 \mathrm{~mm}$. None of the two previous estimators pertain to mobile bed boundary layers (as discussed further in section III). Experiments of [Berni et al., 2013] indicate that the boundary layer thickness can be as thick as $20 \delta$ (nearly $2 \mathrm{~cm}$ ), exceeding the predicted value given by (2). This seems to indicate that vertical momentum diffusion in the case of a mobile bed is stronger than in the fixed bed case.

The aim of this paper is to develop a novel strategy to take into account the effect of loose bottom vertical motions on the near bed velocity profiles and vertical momentum diffusion through a 1D $k-\omega$ RANS model.

\section{METHODS}

\section{II.1. Experimental set-up and wave conditions}

The experiments took place in the LEGI wave flume, with nonlinear waves propagating over a scaled beach profile made of loose material (figure 1). The flume is $36 \mathrm{~m}$ long, $55 \mathrm{~cm}$ wide and $1.30 \mathrm{~m}$ high. The bottom granular material is made of plastic particles of low density $\left(\rho_{s}=1,180\right.$ g.L. $\left.\mathrm{L}^{-1}\right)$ and of median diameter $d_{50}=0.64 \mathrm{~mm}$, ensuring a Froude and Shields similitude [see extensive details in Grasso et al., 2009]. The elementary wave forcing used in the experiments is the combination of two single bichromatic wave packets of carrier period $T=2.5 \mathrm{~s}$ and $T=3 \mathrm{~s}$ respectively, combined in one wave sequence. In the present paper we will only analyze the dynamics of the boundary layer induced by the $2.5 \mathrm{~s}$ wave train (figure 2). The effective experimental forcing consists in 50 repetitions of the wave sequence described above. Before the wave sequence's run, in order to perform reliable phase averages on the free surface and velocity measurements, the experiment was run until the beach profile reached a quasi-equilibrium [Berni et al., 2013]. Phase averages were performed over the last 29 wave trains. Furthermore, in the subsequent analysis we have selected a specific $10 \mathrm{~s}$ interval in each of these 29 wave trains. This interval is made out of four waves of similar amplitude and shape in the middle of the wave packet (see figure 3 ). The average breaking point was roughly stationary at $\mathrm{x} \approx 9 \mathrm{~m}$. Velocity time series were verified so that spikes associated to the presence of air bubbles (especially in the surf zone) did not represent more than 3 to $5 \%$ of the measured points.

\section{II.2. Bed level measurements}

Since the waves propagate on a loose bed, we define the instantaneous still bed position, $z_{b}(t)$, as the elevation of the limit between the moving fluid-sediment mixture and the motion-less sediment bed (see figure 4). The moving fluid-sediment mixture contains the sheet flow layer. The instantaneous position of the still bed and the evolution of the horizontal cross-shore velocity vertical profile were obtained with a vertical spatial resolution close to $3 \mathrm{~mm}$ by using an Acoustic Doppler Velocity Profiler (ADVP). The mean water depth at the location of the velocity measurements (at $x=13 \mathrm{~m}$ ) was $h=0.125 \mathrm{~m}$. The procedure for collecting the data presented here has been described thoroughly in Berni et al., [2013]. The ADVP is able to detect the top of the sheet-flow layer as well as the bottom of the sheet flow layer representative of the still bed [Berni et al., 2012].

An example of measured instantaneous still bed position is plotted in figure 5. A filtered time series is computed by applying a low-pass filter with a cut-off at $5 \mathrm{~Hz}$. The filtered time series of still bed elevations shows a still bed evolution qualitatively consistent with the external wave velocity forcing: still bed lowering at phases close to the wave crests at the same time as the sheet flow layer develops with an increase in $\delta_{s}$.

The evolution of the still bed position $z_{b}$ can be described by a probability density function (pdf). The mean value of $z_{b}$ is zero. The standard deviation of the instantaneous still bed elevation is $\sigma_{z_{b}}=3.6 \times 10^{-3} \mathrm{~m}$. We show in figure 6 two estimations of the still bed elevation pdf. One is directly the pdf of the raw measurements and the other is deduced from a low-pass filtering of $z_{b}$. In figure 6 a standard Gaussian distribution, with this same standard deviation $\sigma_{z_{b}}$ is also plotted. It appears to be close to the experimental pdf of the non-filtered still bed elevation. The still bed positions are seen to essentially remain in a strip of width $\pm 5 \delta \approx \pm 5 \mathrm{~mm}$ ( $\delta$ being the Stokes length (1)).

\section{II.3. Velocity measurements}

As indicated previously the ADVP provides instantaneous velocity measurements at $50 \mathrm{~Hz}$. A clip of the instantaneous velocity time series is shown in figure 5. This clip is a part of the 29 clips used for the ensemble averaging given in figure 3. Notice that the record shows the signature of turbulent fluctuations some of which are stronger at flow reversal (see also the $-5 / 3$ slope in the power spectra shown in [Berni et al., 2013]). Instantaneous velocities at $x=13 \mathrm{~m}$ also show pinched crests and secondary crests velocities associated to highly non linear wave propagation inside the surf zone also evidenced by the spectral analysis presented by Berni et al., [2013]. Waves are also asymmetric with steep wave fronts and gentle seaward slopes. These last features are a consequence of wave breaking occurring a few meters before the measurement point.

The skewness and the asymmetry are key tools to analyze the nonlinear characteristics of the flow. The dimensional skewness $S k$ vertical profile and the dimensional asymmetry $A s$ vertical profile of the velocity time series are computed from measured time series using formula (3-4):

$$
\begin{aligned}
& S k(z)=\overline{(u(z, t)-\bar{u})^{3}} \\
& A s(z)=-\overline{\mathfrak{J}(H(u))^{3}}
\end{aligned}
$$

where $u(z, t)$ is the cross-shore horizontal velocity, with the overbar denoting a time-average over the studied 


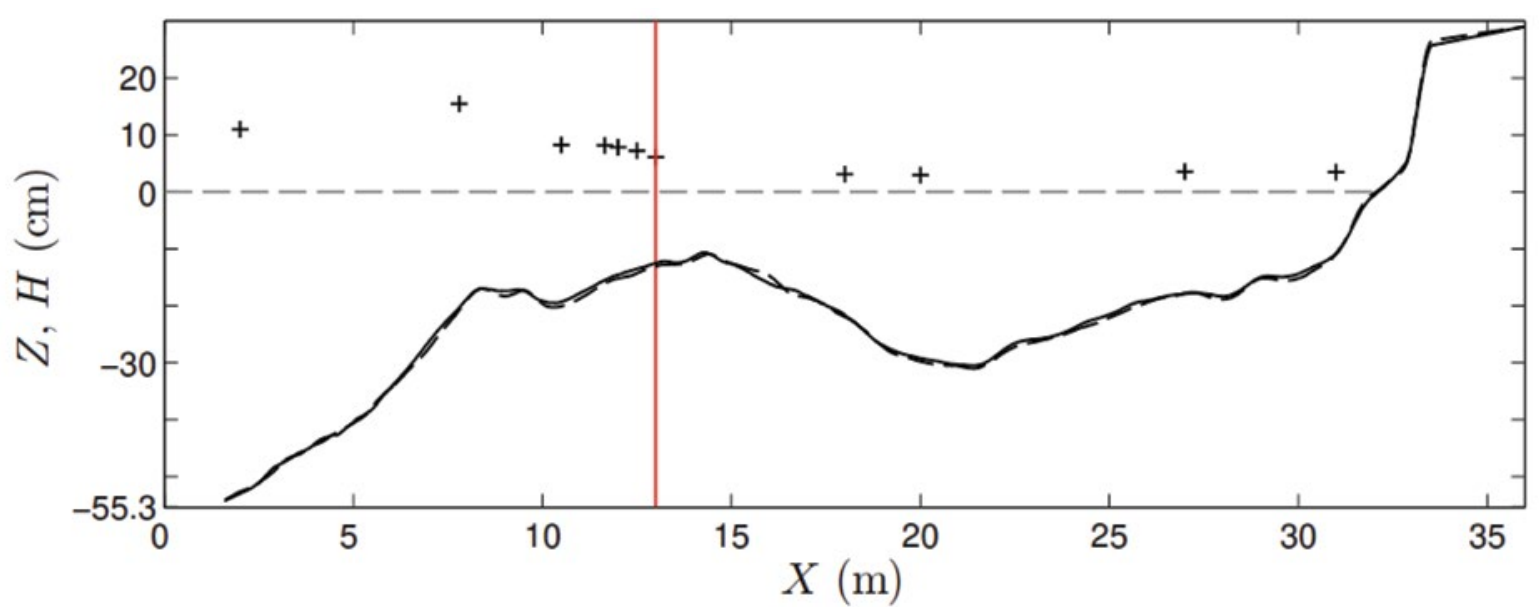

Figure 1: Experimental cross-shore bed profiles. Smoothed cross-shore profile of the bed elevation. Solid and dashed black lines correspond to bed profiles separated by 50 wave trains of wave action. The horizontal dashed grey line represents the still water level. The black crosses indicate the mean wave height $H$ of the wave train. The ADVP was located at $x=13 \mathrm{~m}$, indicated by the red vertical line.

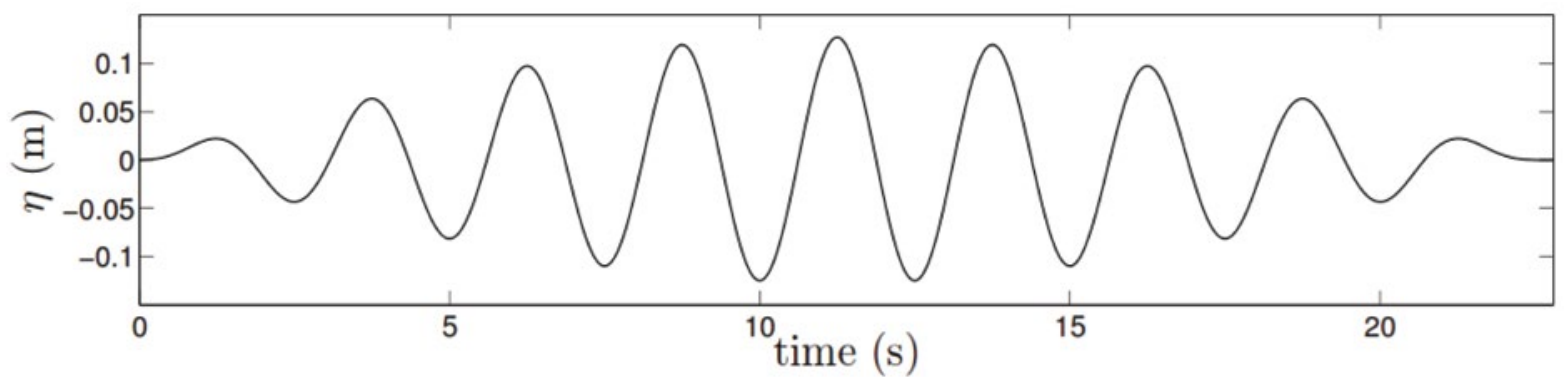

Figure 2: The wave forcing. Prescribed bichromatic free surface displacement $\eta$ at the wavemaker. The carrier wave period is $T=2.5 \mathrm{~s}$.

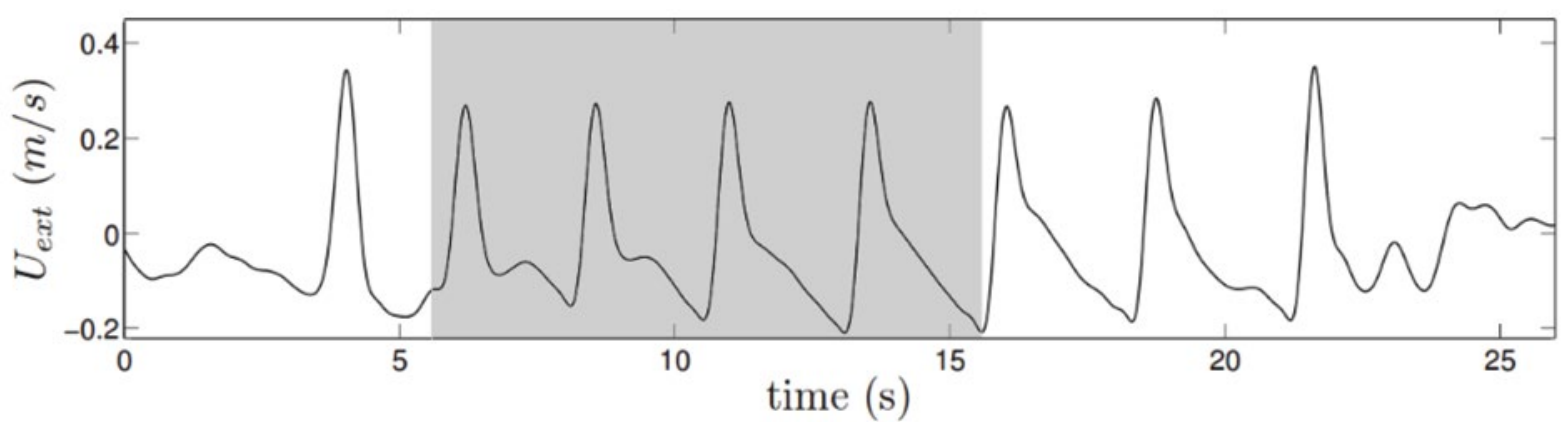

Figure 3: Free stream velocity. Phase averaged velocity records of the $2.5 \mathrm{~s}$ wave packet at the cross-shore position $x=13 \mathrm{~m}$ and at an elevation of $z=3.6 \mathrm{~cm}$ above the mean bed elevation. The grey-tinted box bounds the waves used in the analysis.

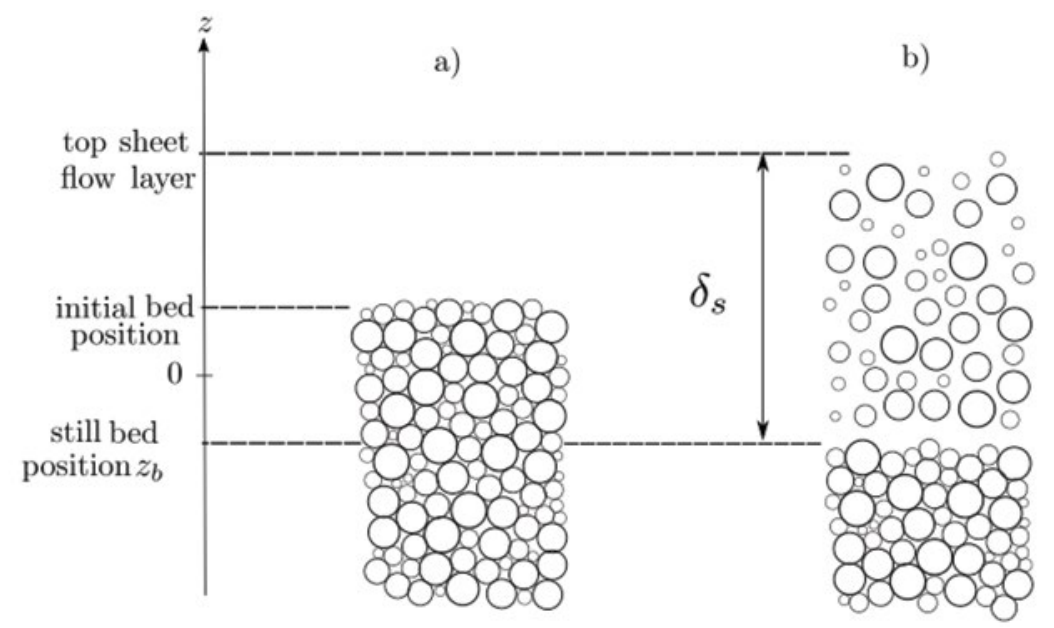

Figure 4: Schematic of the bed evolution. $z=0$ is the average position of the still bed and $z_{b}$ is the position in time of the still bed level. a) near-bed configuration prior to wave forcing; b) bottom configuration during wave action. $\delta_{s}$ represents the sheet flow layer thickness. 

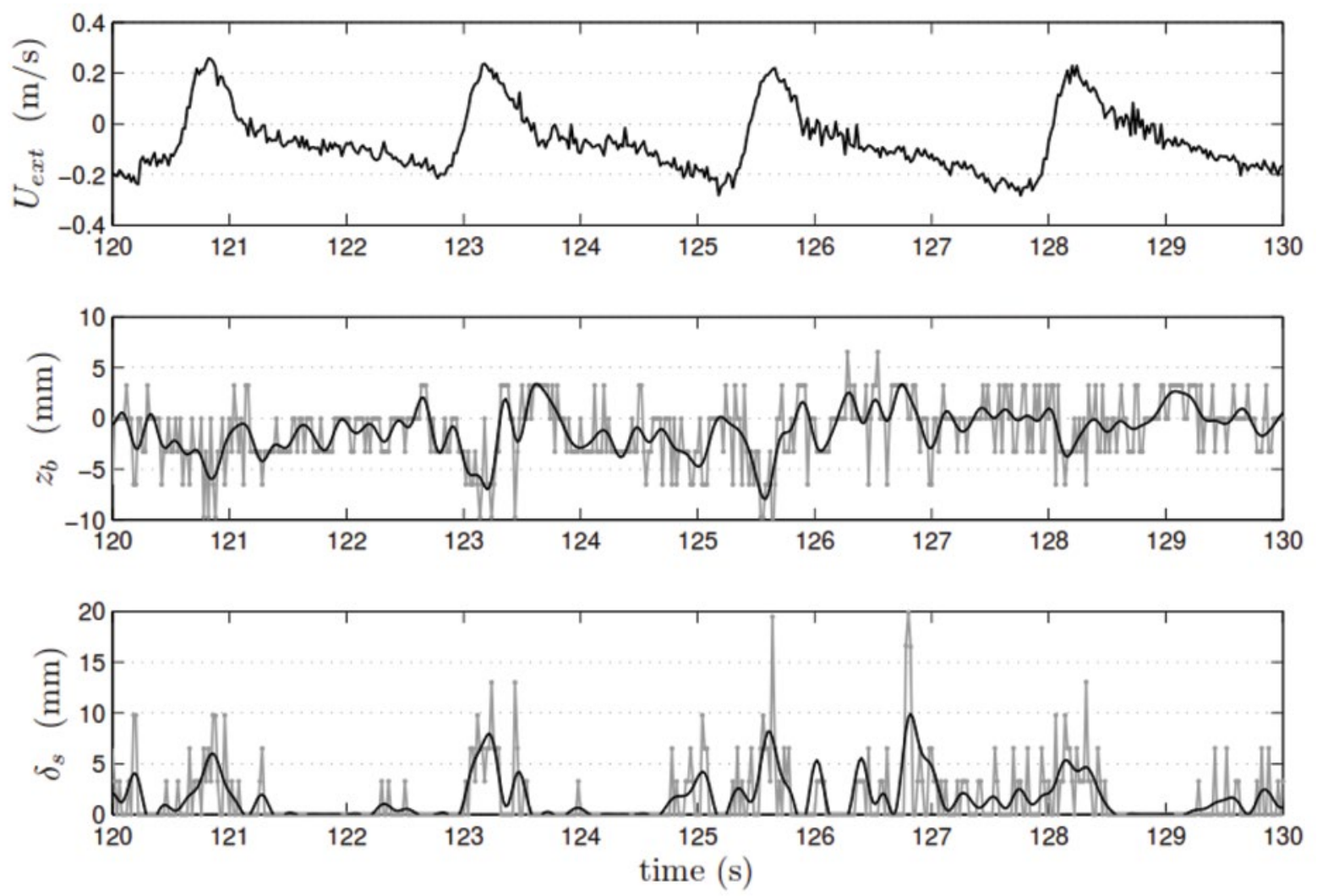

Figure 5: Instantaneous velocities, still bed levels and sheet-flow layer thickness. Top panel: one of the 29 records of instantaneous free stream velocity at $z=3.6 \mathrm{~cm}$; middle panel: still bed displacements phased with the velocities in the top panel. Bottom panel: sheet flow layer thickness $\delta_{s}$ also phased with the velocities. Thin grey line: instantaneous still bed elevations; Thin black line: low-pass filtered still bed elevations.

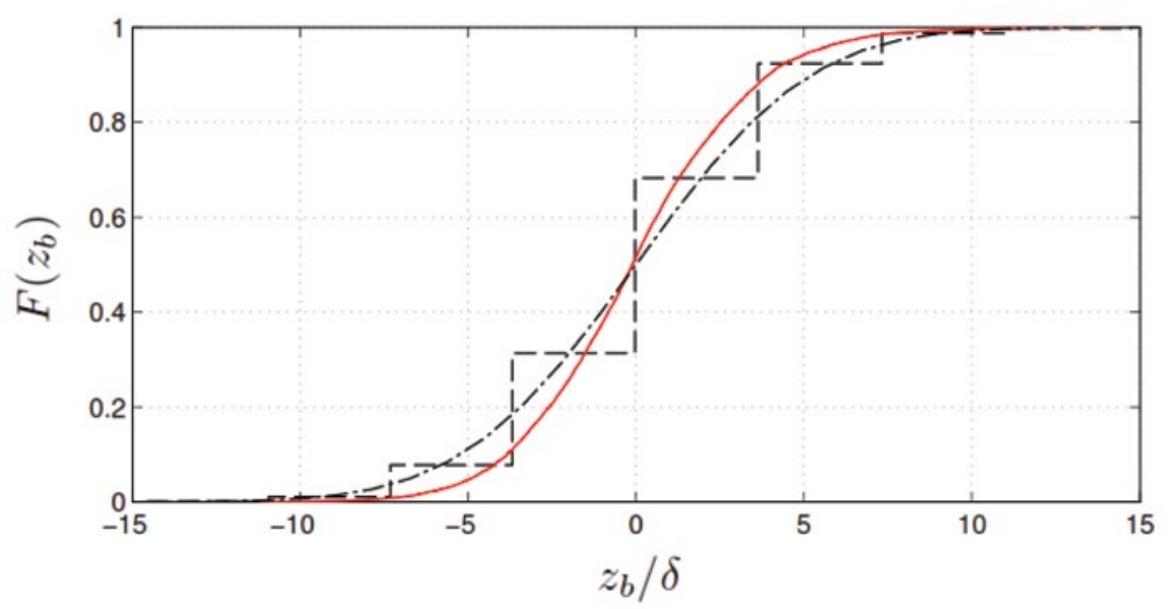

Figure 6: Cumulative frequency distribution. dashed line: instantaneous still bed pdf; dot/dashed line: low-pass filtered still bed pdf; plain line: gaussian pdf with the same standard deviation as the instantaneous still bed displacements.

interval, $H(u)$ is the Hilbert transform of $u$ and $\mathfrak{I}$ the imaginary part.

The time averaging of velocity measurements at vertical positions that can be alternatively in the flow or inside the bed requires a specific treatment. Indeed some measuring volumes of the ADVP can at some instances be below the still bed level. When this happens the ADVP does not provide a reliable velocity value. It is decided to prescribe a 0 value of the velocity for this case. It is physically sound to do so since the Eulerian velocity of the sediment/fluid mixture can be reasonably approximated to 0 when the latter occurs. Such a procedure was applied to the data of Berni et al., [2013] presented here. As the $z=0$ elevation, corresponding to the mean still bed level, is $50 \%$ of the time below the still bed level, $50 \%$ of the time series is padded with zeros. Moreover the point at $z \approx-4 \delta$ (see fig. 7) is found to be in the moving sediment/fluid mixture roughly $20 \%$ of the time and therefore about $80 \%$ of the time series is padded with zeros. 
The effect of this procedure can be evaluated for the root mean square velocity $u_{r m s}$ computed as:

$$
u_{r m s}(z)=\sqrt{\overline{(u(z, t)-\bar{u})^{2}}}
$$

where the time series is padded with zeros following the procedure explained above. The vertical profile of $u_{r m s}$ is given in figure 7 and note that below $z=0, u_{r m s}$ is very small. The velocity series padded with zeros are also used to compute $S k$ and $A s$ according to equations (3) and (4), respectively.

\section{II.4. Numerical model}

The horizontal mean velocities near the bed are numerically computed with a $1 \mathrm{DV} k-\omega$ turbulent boundary layer model in a Low Reynolds Number version ([Guizien et al., 2003; Wilcox, 2006]). The turbulent kinetic energy $k$ equation includes cross-correlation terms between the gradient of $k$ and the gradient of $\omega$ (specific dissipation rate) to accommodate for adverse pressure gradients. The bottom boundary condition on the turbulent kinetic energy $k$ is $d k / d z=0$ as suggested by Fuhrman et al., [2010] in order to specifically mimic a rough bottom boundary instead of $k=0$ that inevitably forces a viscous sub-layer whatever the Reynolds number is. Additionally the boundary Nikuradse equivalent roughness $k_{s}$ is prescribed in the wall boundary condition for $\omega$.

The nonlinear equations for the horizontal velocity $u$, the turbulent kinetic energy $k$ and the specific dissipation rate $\omega$ are discretized using an implicit finite control volume method [Patankar, 1980], with a staggered grid for $k$ and $\omega$. The algebraic equations resulting from the discretization were solved implicitly in time by linearizing the non-linear terms.
The model is forced with the time series of the measured (free-stream) velocity at elevation $z=2 \mathrm{~cm}$ where $u_{r m s}$ is maximum. The computational grid on the vertical is a classic geometric grid of 200 nodes from $z_{0}=10^{-6} \mathrm{~m}$ to $z=2 \mathrm{~cm}$. The convergence of the numerical model is estimated considering that the time-series input length as a pseudo-period. The numerical model is iterated computing its results within the entire time series and pseudo-period, the velocity relative error between 2 pseudo-periods is estimated as:

$$
\operatorname{err}_{u}=\frac{\left\|u_{1}-u_{0}\right\|_{2}}{\left\|u_{0}\right\|_{2}}=\sqrt{\frac{\sum_{z} \sum_{t}\left(u_{1}(z, t)-u_{0}(z, t)\right)^{2}}{\sum_{z} \sum_{t} u_{0}(z, t)^{2}}}
$$

where $u_{0}(z, t)$ represents the solution of the previous pseudo-period, and $u_{l}(z, t)$ the solution of the current pseudo-period. The convergence is reached by iterating the entire time-series until err ${ }_{u}$ is lower than the desired precision taken as $10^{-6}$.

Stratification effects have been neglected in this paper as sediment particles can be considered as massive, the ratio of their settling velocity to the shear velocity is of order unity or lower, therefore a low suspension is observed. Stratification effects are clearly observed with fine sand (i.e. high ratio of settling velocity to shear velocity) but not with medium sand [O'Donoghue and Wright, 2004]. The processes responsible for the damping of turbulence in the dense sheet-flow layer is still an open question and it is thought that stratification is not the key mechanism.

\section{RESULTS}

Simulations with the $k-\omega$ numerical model on a fixed bed placed at $z=0$, are plotted in figure 7 and 8 . On these
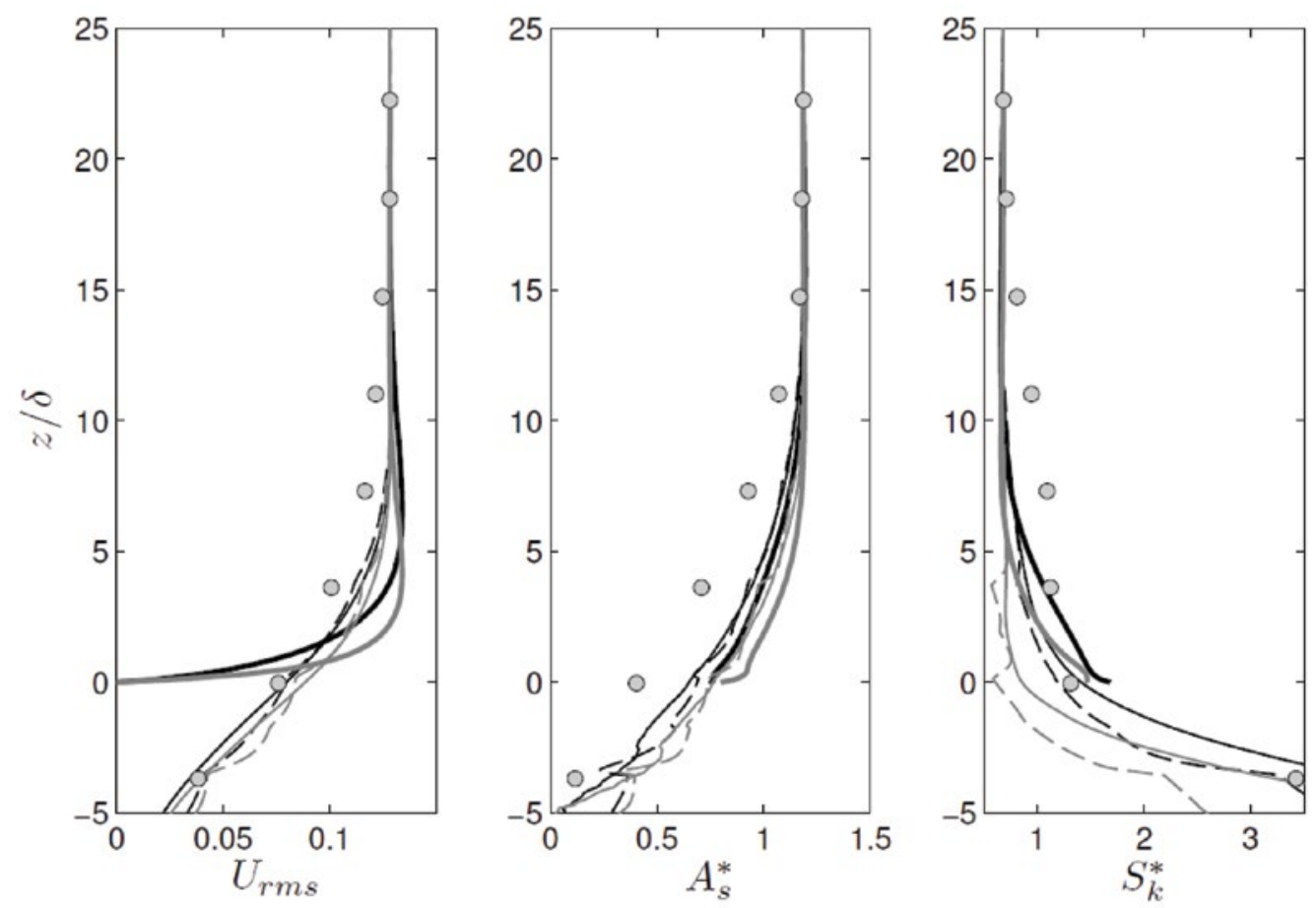

Figure 7: Orbital velocity, dimensionless asymmetry and dimensionless skewness. Left panel: orbital velocity; middle panel non-dimensional velocity asymmetry; right panel: non-dimensional velocity skewness. Grey bullets: experimental data; black lines: computations with (8); grey lines: computations with (7); Thick lines: fixed bed computations; thin lines: computations with the low-pass filtered still bed positions in (9); dashed thin lines: computations with the instantaneous still bed positions in (9). 

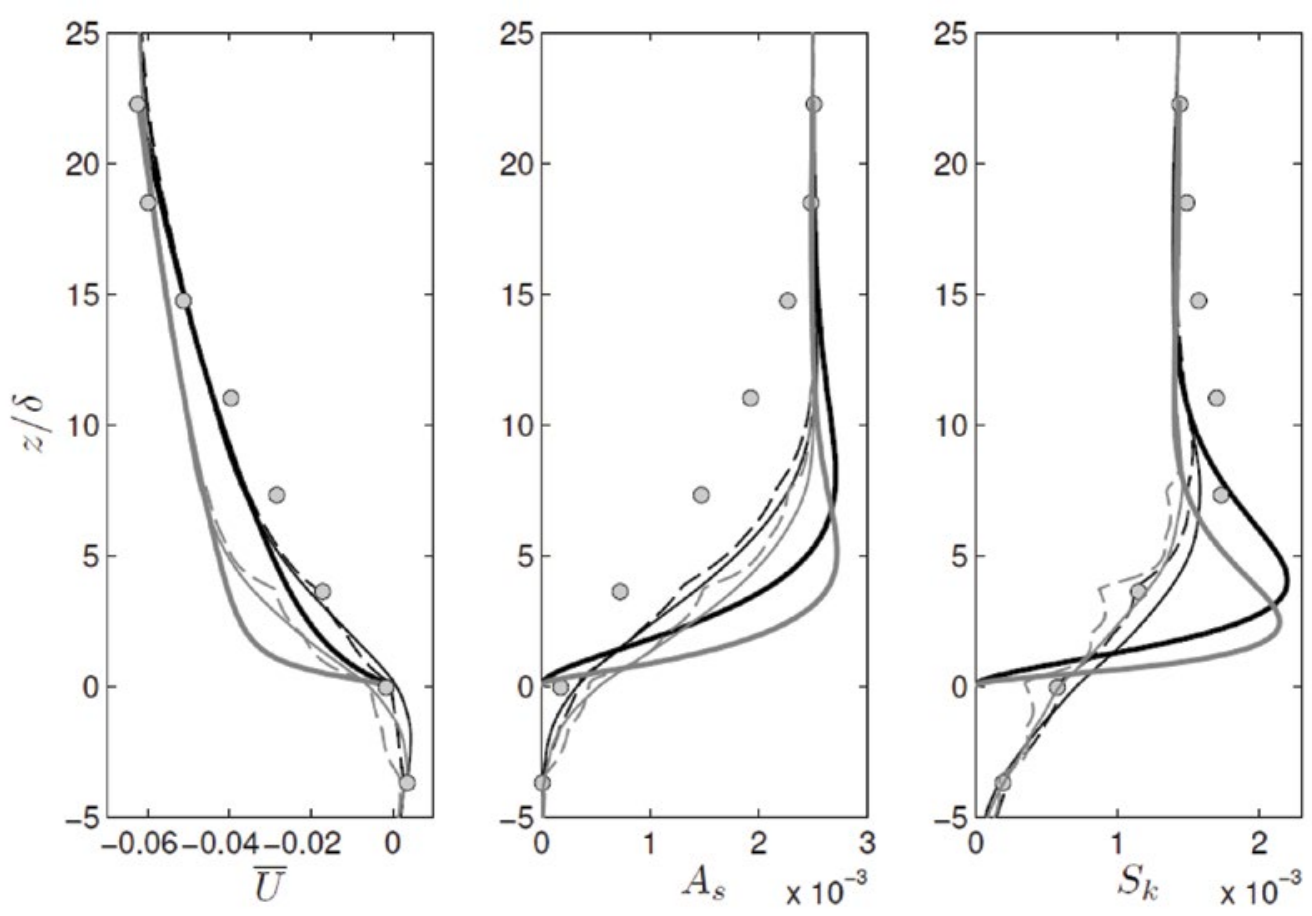

Figure 8: Mean velocity, dimensional asymmetry and skewness. Left panel: mean velocity; middle panel dimensional velocity asymmetry; right panel: dimensional velocity skewness. For the rest, same legend as fig.7.

plots two different runs with two roughness height $k_{s}$ are given. One is the parametrization by Wilson,[1989] for uniform steady sheet flows:

$$
k_{s}=5 \theta d_{50}
$$

and the other is the one provided by Nielsen, [2005] related to measurements on flat sand mobile bed:

$$
k_{s} \approx 70 \sqrt{\theta} d_{50}
$$

where $\theta$ is the Shields number of the flow.

The numerical results obtained using relation (8) show a larger vertical diffusion of momentum as expected compared to the simulation with the relation (7) but the maximum computed $u_{r m s}$ is located at $z=5 \delta$, while the maximum experimental $u_{r m s}$ is at $z=23 \delta$. The vertical shape is also qualitatively different. Indeed the fixed bed computations show an over-shoot in orbital velocity not evidenced in the experiments. The dimensional skewness and asymmetry vertical profiles are also qualitatively very different. Moreover maximum skewness value is over-predicted by the model computations on fixed bed. The non-dimensional values of the skewness $S k^{*}\left(S k^{*}=S k / u_{r m s}^{3}\right)$ and asymmetry $A s^{*}\left(A s^{*}=A s / u_{r m s}^{3}\right)$ are plotted in figure 7. Because $u_{r m s}$ decreases towards the bottom more rapidly than the skewness, the $S k^{*}$ strongly increases closing up on the bottom. This result already shown by Berni et al., [2013] is in line with those of Henderson et al., [2004] for in-situ measurements. Experimental profiles show a much stronger vertical spreading than numerical results not to mention that the model cannot predict velocities below $z=0$ even though fluid flows there from time to time. Above $z=0$ all experimental dimensional values are smaller than the model predicted ones.
To explain such qualitative behavior we hypothesize that the upward vertical motions of the still bed is producing an upward flux of small horizontal momentum in regions of higher momentum while the opposite occurs for downward motions of the still bed. This induces velocities larger than 0 below $z=0$ and velocities smaller than on a fixed bed above $z=0$. This effect acts as a supplementary vertical diffusion that cannot be accounted for even when choosing very strong bed roughnesses. To quantitatively reproduce this phenomenon we combine vertical still bed motion information with the $k-\omega$ computations.

Associated to the free stream velocity time series the model computes times series of the velocity $u(z, t)$ at different elevation. Moreover synchronized with the free stream velocity time series, the experimental data provides $z_{b}(t)$ which is used to define a new velocity time series as,

$$
\begin{gathered}
u^{\prime}(z, t)=u\left(z-z_{b}(t), t\right) \text { for } z>z_{b} \\
u^{\prime}(z, t)=0 \text { for } z \leq z_{b}
\end{gathered}
$$

For this new times series the still bed elevation $z_{b}$ can either be the low pass filtered or the instantaneous one (fig.6). In replacing the original time series by this new one it is implicitly assumed that the boundary layer adapts instantaneously to each still bed position.

Substituting $u$ ' for $u$ in (3), (4) and (5) defines postprocessed $u_{r m s}$, skewness and asymmetry. These new estimates are also plotted in figure 7. Dimensional skewness and asymmetry are plotted in figure 8 along with the mean velocity. The improvement on all quantities is obvious. The novel technique is particularly effective for the mean velocity $\bar{u}$ and the skewness. The improvement on the vertical profile of the asymmetry is not as good. However the 
qualitative shape is close. The mean velocity $\bar{u}$ vertical profile shows that an undertow is present in the experiments compensating for the Stokes mass flux drift and roller induced mass flux. This undertow is present in the free stream velocity and what the novel $1 \mathrm{DV}$ model reproduces is the correct vertical structure within the boundary layer.

\section{CONCLUSION}

A post-processing combining the results of the improved version of a RANS 1DV $k-\omega$ model and data of bottom vertical displacements was successfully used to retrieve vertical profiles at different phases of the horizontal velocity (root mean square velocity, asymmetry and skewness). The enhanced vertical diffusion was found to be due to the vertical motion of the (still bed) boundary rather than to an increase in roughness height. The vertical displacement of the bottom boundary contributes to momentum transfer within the mobile bed and just above. Future work will be focused on the modeling of such vertical bottom motions within the $k-\omega$ framework.

\section{ACKNOWLEGMENTS}

We are indebted to Jean-Marc Barnoud, Muriel Lagauzère and Pierre-Alain Barraud for providing the technical support of the experiments. This study was partly funded by the project MODLIT (DGA-SHOM/INSU-RELIEFS), the project BARCAN (INSU-LEFE), the BARBEC project (ANR No. 2010JCJC60201) and the MEPIERA project of Grenoble INP. The first author would like to acknowledge the support of CONICYT of Chile through PhD grant No.21100415. R. Cienfuegos acknowledge partial support from Conicyt Fondap program No.15110017.

\section{REFERENCES}

BAilard J. A. (1981) - An energetics total load sediment transport model for a plane sloping beach. doi10.1029/ JC086iC11p10938. Journal of Geophysical Research. 86(C11)
Berni C., Barthélemy E., And Michallet H. (2013) - Surf zone cross-shore boundary layer velocity asymmetry and skewness: an experimental study on a mobile bed. Journal of Geophysical Research: Oceans. 118(4) 2188-2200

Berni C., Michallet H., And Barthélemy E. (2012) Measurements of surf zone sand bed dynamics under irregular waves. European Journal of Environmental and Civil Engineering. 16(8) 981-994

Fuhrman D. R., Dixen M., And Jacobsen N. G. (2010) Physically-consistent wall boundary conditions for the k- $\omega$ turbulence model. Journal of Hydraulic Research. 48(6) 793-800

Grasso F., Michallet H., Barthélemy E., And Certain R. (2009) - Physical modeling of intermediate crossshore beach morphology: Transients and equilibrium states. Journal of Geophysical Research. 114(C09001)

Guizien K., Dohmen-Janssen C. M., And Vittori G. (2003) $1 \mathrm{dv}$ bottom boundary layer modelling under combined wave and current: suspension ejection events and phase lag effects. Journal of Geophysical Research. 108(C1)

Henderson S. M., Allen J. S., And Newberger P. (2004) Nearshore sandbar migration predicted by an eddy-diffusive boundary layer model. Journal of Geophysical Research. 109(C05025)

NiElSEN P. (2005) - Coastal bottom boundary layers and sediment transport. World Scientific Publishing Company Incorporated, third edition.

O'DONOGHUE T. AND WRIGHT S. (2004) — Flow tunnel measurements of velocities and sand flux in oscillatory sheet flow for wellsorted and graded sands. Coastal Engineering. 51 1163-1184

Patankar S. V. (1980) - Numerical Heat Transfer and Fluid Flow. Taylor and Francis Group

Ruessink B. G., Van Den Berg T. J. J., And Van Rijn L. C. (2009) - Modeling sediment transport beneath skewed asymmetric waves above a plane bed. Journal of Geophysical Research. 114(C11021)

Sleath J. F. A. (1987) - Turbulent oscillatory flows over rough beds. Journal of Fluid Mechanics. 182 369-409

Wilcox D. C. (2006) - Turbulence Modeling for CFD. DCW Industries, Inc., La Canada, Calif., 3rd edition

WiLson K. C. (1989) - Mobile-bed friction at high shear stress. Journal of Hydraulic Engineering. 115(6) 